\title{
New developments in family demography
}

\author{
Sabu S. Padmadas ${ }^{1} \cdot$ Zhenzhen Zheng $^{2} \cdot$ Baochang Gu ${ }^{3}$
}

Published online: 29 January 2021

(c) China Population and Development Research 2021

The beginning of the 21 st century witnessed unprecedented economic and social transformation across the globe, underpinned by a steady rise in human and social capital, and per-capita income. Rapid urbanisation, industrialisation and modernisation have also created the so-called middle-class boom in Asian societies, triggering family change driven by higher aspirations, modern lifestyles and new forms of consumer behaviour. On the other hand, economic and social inequalities have almost simultaneously widened across different social strata, increasing the complexity of family structures and living arrangements.

Most countries in Asia have now reached the final stage of the first demographic transition (FDT), with death rates almost exceeding birth rates. The rapid decline in under-five mortality rates over the last two decades had significant impact in not only reducing fertility rates below replacement level but also increasing population longevity, unprecedentedly. This global phenomena is so apparent, even more so amongst the emerging economies within Asia, particularly China and India. While most countries in Eastern and South-Eastern Asia have already experienced a fertility below replacement or sub-replacement level, those in Southern Asia are rapidly converging towards below replacement levels.

With sustained reduction in fertility levels below replacement level, we have seen an intensification of sex ratios in favour of sons especially in China and India. On the other hand, there is an upward social mobility across generations, as parents tend to invest and allocate more resources on their children's education, health and wellbeing. In addition, children born in small or one-child families have greater economic advantage of inheriting wealth and assets from their parents and the grand parents from the father's and mother's side. In fact, for the first time ever in human history, we see an emerging trend in the co-existence of multiple generation of children, parents, grandparents and great grandparents.

Sabu S. Padmadas

S.Padmadas@soton.ac.uk

1 University of Southampton, Southampton, UK

2 Chinese Academy of Social Sciences, Beijing, China

3 Fudan University, Shanghai, China 
Alongside, there is evidence of ideational change in Asian societies, marked by a dramatic shift from altruistic to more individualistic attitudes and behaviours. Dirk van de Kaa and Ron Lesthaeghe attributed these behavioural and attitudinal changes as part of a second demographic transition (SDT) in western societies, driven by shift in family relations from "king-child with parents" to "king-couple with child", or even no children. Consequently, pluralistic families emerge in various forms, including a rise in pre-marital cohabitation as a means to delay or replace marriage and postpone childbearing, marital and cohabitation dissolutions, independent living or living apart together as both couple tend to be economically favourable. There is also an emergence of single headed households, with a sizeable proportion of young people choosing to delay formal partnerships or live alone as cubicle dwellers within their own virtual peer network.

With the increase in human and social capital, we expect further increase in educated females being skilled to compete in the labour market, and occupy key positions. There is already growing evidence of economic independence among women in contemporary Asian societies. The high cost of living in urban areas and cities has also forced dual-income households and increasingly women as sole breadwinners of the family. Better educated women tend to shift themselves to be career oriented rather than family focused, and childbearing thus likely becomes subordinate to the professional development in life aspiration. Technology, especially social media, internet and artificial intelligence supported systems, will play a critical role in influencing reproductive behaviours and intergenerational care provision. The changes in intergenerational transfers are likely to operate in both directions in terms of financial, non-financial and emotional support, especially with high levels of human mobility and migration.

This edition of China Population and Development Studies presents original research in family demography including three papers from China, one from India and another one from Iran.

JUHUA YANG and SHENGHONG DU bring a historical perspective of family change over the last 70 years in China by synthesising data from national population censuses, one percent population surveys and survey resources. Their analyses reaffirm the pertinent role of socioeconomic and demographic transformation triggering changes in family structure in China. The paper provides an interesting narrative of family change reflecting on the six stages of family cycle including formation, expansion, stability, contraction, empty nest and dissolution. The authors highlight the overarching influence of social and economic investments, alongside stringent family planning interventions, triggering unprecedented and rapid demographic transition and family change over the last three decades. In particular, the rising trends and acceptance of premarital cohabitation, with young people substituting marriage by cohabitation or at least as a means to delaying marriage and family formation.

A rippling effect of China's unique family planning policy is the dominance and persistence of one-child families across more than one generation. Unlike their previous generations, the one-child families have had an exceptional life cycle experience in terms of allocating greater resources and investment on their only child. They have also had the opportunity to see their offspring graduating from universities, 
entering labour market, finding a partner, getting married and having a family of their own. On the other hand, a substantially large cohort of one-child couples has already entered into older ages, and a majority of these couples now experience an empty nest syndrome. This trend has become quite visible in both urban and rural areas of China.

HAIXIA WU analysed population data from China's five provinces to investigate the characteristics of empty nest elderly one-child parents in urban China. Wu finds that the empty nest is characterised couples at various stages in their lifetime including the only child leaving home for the university, entering labour market, entering marriage, having children and so forth. On an average, the only-child couple is likely to remain in an empty nest state for about a decade and some for almost a quarter of a century. The empty nest is transient in nature depending on the life course stages, and intergenerational needs and support.

The empty nest syndrome among elderly couples is a ground reality in contemporary China. Older parents in an empty nest does not necessarily imply isolation and emotional distress, as individual preferences tend to vary among older people by social, economic, demographic and geographic characteristics. Moreover, it depends on the community where older people live and the extent of their social interactions with neighbours and friends. There is, however, a clear demographic influence determining the risk of adverse outcomes for empty nesters. The risk could be potentially higher for very old couples or those living alone, especially in the absence of social welfare support and care provision. Among other characteristics, the gender of the only child is a determinant of empty nest, with the only-son parents to be at a higher risk of empty nest than those with the only-daughter parents.

The consequences of gender preferences and long-term distortion in sex ratios have also exacerbated the timing of marriage and male marriage squeeze in rural China. ISABELLE ATTANÉ conducted statistical analysis of data from three rural counties of Shanxi province to demonstrate the influence of socioeconomic inequalities in male marriage squeeze. The analyses provide compelling evidence of delaying trends in marriage among men across marriage cohorts, and those who eventually marry have larger age difference with their spouses. The perceived shortage of women and the poor economic circumstances of men partly explain the male marriage squeeze phenomenon. The paper further explores various considerations for marriage by single men and concludes with a speculation of possible female social hypergamy underpinning marriage squeeze among economically disadvantaged older men in rural China.

As China gears towards rapid urban transformation with changing lifestyles and high cost of living, the future generation of young men in China may find new courtship and mating strategies and seek long-term stable cohabitation unions. There is already monetization of marriage in China and elsewhere in Asia, driven by the rising cost of wedding ceremonies, gift tokens and increasingly agent or matchmaker fee.

In this edition, ANKITA CHAKRABARTI proposes a Gender Status Index to examine whether a woman's position as the head of household makes any difference in terms their capabilities, economic opportunities and agency including participation in civil and public politics across different states in India. Her 
findings show significant gender differences highlighting that a female holding the position of household head, as a provider and a caregiver, has no bearing on her social status. The study concludes that women in India lack control over resources and agency, which explains the inherent female disadvantage in social space and labour market.

The position of women in a society is a critical factor associated with reproductive attitudes, decisions and behaviours. Women in China had little choices but to follow the official family planning policy and the vast majority had only one child. Prior to this, the family planning policy in China advocated a "later, longer and fewer" strategy during the 1970s, which then continued alongside a restricted "one-child policy" across generations. The introduction of open market economy and the transition towards one-child families enabled better employment opportunities for women in China. Gender gap in wages and discrimination persisted, and most women were employed in low productivity sectors. On the other hand, the female labour force participation rate in China is as high as over 60 percent and in comparison, only 22 percent of women in India are economically active. In India, most women enter marriage relatively early and start childbearing even before finishing their secondary education.

Finally, FATEMEH TORABI and NASIBEH ESMAEILI applied an integrated Neural Network and Wavelet Mathematical model on national data to validate and predict short-term trends in divorce rates. The authors confirm the reliability and accuracy of Neural-Wavelet Network model to modelling divorce data, highlighting a continuing upward trend in divorce rates until 2027. The analysis presented is computationally intensive without any scenarios or assumptions but makes a strong case for calling urgent interventions to tackle the rising divorce rates in the country.

Unlike its neighbouring countries, the Islamic Republic of Iran took a U-turn in family planning history towards the last decade of the twentieth century encouraging couples to limit their family size to three children. Between 1990 and 2000, Iran's total fertility rate dropped from an average of 5.6 children per woman to below replacement fertility rate (1.9). The revived family planning policy was strongly supported and advocated by political and religious leaders, promoting both temporary and permanent methods of contraception, and embracing small family as social responsibility for nation's social and economic development. During the course of transition from a traditionally high fertility to modern low fertility society, Iran witnessed unprecedented increase in divorce rates-attributed to individual, family and sociocultural factors. In addressing the implications of rising divorce rates on family dissolutions and living arrangements of children, the government has already initiated measures to monitor and prevent divorces in the country.

The five papers included in this series present data on some emerging trends, types and patterns of family living arrangements in the Asian context. The findings provide interesting reflections and insights for policy and programme intervention. There is a need for further rigorous population level comparative analysis of panel data to monitor family change and related behaviours on a continuous basis, considering different population sub-groups such as youth and migrants. 


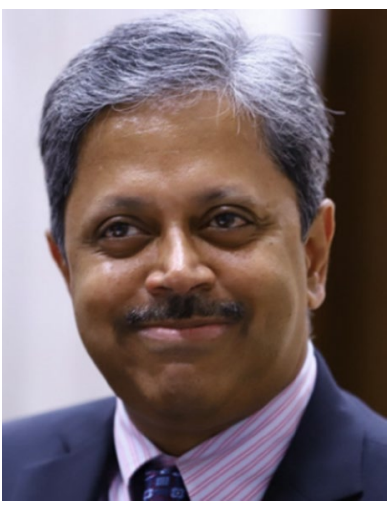

Sabu S. Padmadas is Professor of Demography and Global Health at the Department of Social Statistics and Demography, and Associate Dean International of the Faculty of Social Sciences at the University of Southampton in the United Kingdom.

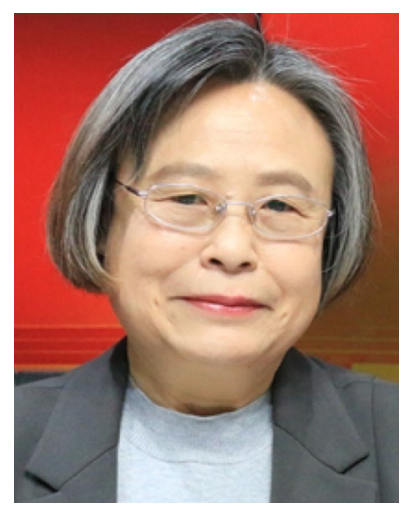

Zhenzhen Zheng is a Professor at the Institute of Population and Labor Economics, Chinese Academy of Social Sciences. She is also a Research Fellow of the Center for Healthy Aging and Development Studies, National School of Development, Peking University.

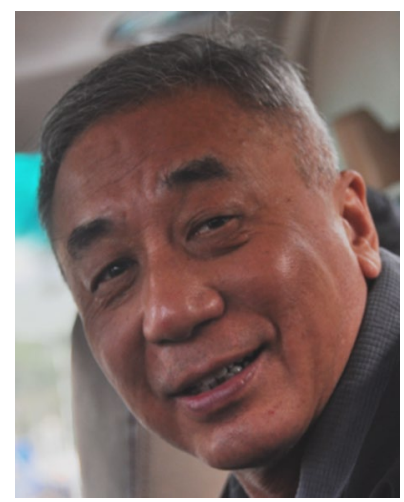

Baochang Gu is a Professor and Senior Research Associate at Center for Population and Development Policy Studies, Fudan University, Shanghai. 